\title{
Vacuolar-ATPase-mediated intracellular sequestration of ellipticine contributes to drug resistance in neuroblastoma cells
}

\author{
JAN HRABETA ${ }^{1}$, TOMAS GROH ${ }^{1,2}$, MOHAMED ASHRAF KHALIL $^{1}$, JITKA POLJAKOVA ${ }^{2}$, VOJTECH ADAM ${ }^{3,4}$, \\ RENE KIZEK $^{3,4}$, JIRI UHLIK ${ }^{5}$, HELENA DOKTOROVA ${ }^{1}$, TEREZA CERNA ${ }^{2}$, EVA FREI ${ }^{6}$, \\ MARIE STIBOROVA $^{2}$ and TOMAS ECKSCHLAGER ${ }^{1}$ \\ ${ }^{1}$ Department of Pediatric Hematology and Oncology, Second Medical School, Charles University and \\ University Hospital Motol, 15006 Prague; ${ }^{2}$ Department of Biochemistry, Faculty of Science, Charles University, \\ 12840 Prague; ${ }^{3}$ Department of Chemistry and Biochemistry, Faculty of Agronomy, Mendel University in Brno, \\ $61300 \mathrm{Brno} ;{ }^{4}$ Central European Institute of Technology, Brno University of Technology, 61600 Brno; \\ ${ }^{5}$ Department of Histology and Embryology, Second Medical School, Charles University, 15006 Prague, Czech Republic; \\ ${ }^{6}$ Division of Preventive Oncology, National Center for Tumor Diseases, \\ German Cancer Research Center (DKFZ), D-69 120 Heidelberg, Germany
}

Received May 2, 2015; Accepted June 8, 2015

DOI: 10.3892/ijo.2015.3066

\begin{abstract}
Neuroblastoma is the most common cancer in infants and the fourth most common cancer in children. Aggressive cell growth and chemoresistance are notorious obstacles in neuroblastoma therapy. Exposure to the anticancer drug ellipticine inhibits efficiently growth of neuroblastoma cells and induces apoptosis in these cells. However, ellipticine induced resistance in these cells. The upregulation of a vacuolar (V)-ATPase gene is one of the factors associated with resistance development. In accordance with this finding, we found that levels of V-ATPase protein expression are higher in the ellipticine-resistant UKF-NB-4 ${ }^{\mathrm{ELLI}}$ line than in the parental ellipticine-sensitive UKF-NB-4 cell line. Treatment of ellipticine-sensitive UKF-NB-4 and ellipticine-resistant UKF-NB-4 ${ }^{\mathrm{ELLI}}$ cells with ellipticine-induced cytoplasmic vacuolization and ellipticine is concentrated in these vacuoles. Confocal microscopy and staining of the cells with a lysosomal marker suggested these vacuoles as lysosomes. Transmission electron microscopy and no effect of an autophagy inhibitor wortmannin ruled out autophagy. Pretreatment with a V-ATPase inhibitor bafilomycin A and/or the lysosomotropic drug chloroquine prior to ellipticine enhanced the ellipti-
\end{abstract}

Correspondence to: Professor Marie Stiborova, Department of Biochemistry, Faculty of Science, Charles University, Albertov 2030, 12840 Prague 2, Czech Republic

E-mail: stiborov@natur.cuni.cz

Professor Tomas Eckschlager, Department of Pediatric Hematology and Oncology, Second Medical School, Charles University and University Hospital Motol, V Uvalu 84, 15006 Prague, Czech Republic E-mail: tomas.eckschlager@lfmotol.cuni.cz

Key words: neuroblastoma, resistance to ellipticine, vacuolation, drug sequestration, vacuolar ATPase cine-mediated apoptosis and decreased ellipticine-resistance in UKF-NB-4 ${ }^{\mathrm{ELLI}}$ cells. Moreover, pretreatment with these inhibitors increased formation of ellipticine-derived DNA adducts, one of the most important DNA-damaging mechanisms responsible for ellipticine cytotoxicity. In conclusion, resistance to ellipticine in the tested neuroblastoma cells is associated with V-ATPase-mediated vacuolar trapping of this drug, which may be decreased by bafilomycin A and/or chloroquine.

\section{Introduction}

Neuroblastoma is a malignant tumor consisting of neural crest derived undifferentiated neuroectodermal cells. These tumors are biologically heterogeneous, with cell populations differing in their genetic programs, maturation stage and malignant potential $(1,2)$. As neuroblastoma cells seem to have the capacity to differentiate spontaneously in vivo and in vitro (3), their heterogeneity could affect treatment outcome. Recent studies have provided a link between increased metastatic potential and drug-resistant phenotypes, indicating that in addition to the development of drug resistance, chemotherapy of tumors may cause changes in their biological characteristics $(4,5)$. Unfortunately, little improvement in therapeutic options in high risk neuroblastoma has been made in the last decade, requiring a need for the development of new therapies.

Recently, we suggested a novel treatment for neuroblastomas, utilizing a drug targeting DNA, the plant alkaloid ellipticine. This compound and its derivatives act as potent anticancer agents via a combined mechanism involving cell cycle arrest and induction of apoptosis. Cell death induced by ellipticine has been shown to engage a p53-dependent pathway, cell cycle arrest, interaction with several kinases and induction of the mitochondrial pathway of apoptotic cell death. Cell cycle arrest was shown to result from DNA damage caused by a variety of tumor chemotherapeutic agents; this is also the 
case for ellipticines. Formation of covalent DNA adducts after ellipticine enzymatic activation with cytochrome P450 (CYP) and peroxidase enzymes is one of the most important mechanisms of its pharmacological action (summarized in refs. 6,7). We found that exposure of human neuroblastoma IMR-32, UKF-NB-3 and UKF-NB-4 cell lines to this agent resulted in strong inhibition of cell growth, followed by induction of apoptosis (6-11). These effects were associated with formation of two major covalent ellipticine-derived DNA adducts, identical to those formed by the CYP- and peroxidase-mediated ellipticine metabolites, 13-hydroxy- and 12-hydroxyellipticine $(6,7,12-16)$.

The levels of covalent ellipticine-derived DNA adducts correlated with ellipticine toxicity in IMR-32 and UKF-NB-4 cell lines. Cells of both lines accumulated in $\mathrm{S}$ phase, suggesting that ellipticine-DNA adducts interfere with DNA replication. We therefore concluded that formation of ellipticine-DNA adducts was the predominant DNA-damaging mechanism of ellipticine action, resulting in its high cytotoxicity to these neuroblastoma cells $(6-8,11)$.

Nevertheless, this drug is unfortunately capable of inducing resistance in neuroblastoma cells. Exposure of UKF-NB-4 cells to increasing concentrations of ellipticine resulted in a resistant line assigned as UKF-NB-4 $4^{\mathrm{ELLI}}(8,17)$. In the UKF-NB- $4^{\mathrm{ELLI}}$ cells, lower accumulation of this drug was found in the nuclei after treatment of these cells with ellipticine than in the parental line (17), which consequently leads to lower levels of DNA adducts and decreased ellipticine toxicity in these cells. Ellipticine resistance in neuroblastoma is caused by a combination of overexpression of Bcl-2, efflux or degradation of the drug, downregulation of topoisomerases and the upregulation of vacuolar (V)-ATPase (17). The mechanism of V-ATPase contribution to induction of resistance to ellipticine in the UKF-NB-4 ${ }^{\mathrm{ELLI}}$ cell line was investigated in this study.

Vacuolar V-ATPase is the multi-subunit membrane protein complex (18) responsible for the acidification of some intracellular compartments such as trans-Golgi network, endosomes, lysosomes and secretory granules. The V-ATPase-dependent acidification of Golgi complex is essential for the synthesis and delivery of the lysosomal hydrolases from endoplasmic reticulum/Golgi to lysosomes (19-21). The acidic microenvironment caused by changes in the $\mathrm{pH}$ gradient between the intracellular and the extracellular compartments as well as the $\mathrm{pH}$ gradient between the cytoplasm and the intracellular organelles can be significantly involved in the mechanism of drug resistance $(22,23)$. These changes in $\mathrm{pH}$ lead to neutralization of weakly basic drugs by the acidic tumor microenvironment or the sequestration of drugs into lysosomal vesicles (22-26). Whether these mechanisms and if so, which of them are responsible for V-ATPase-dependent development of resistance of UKF-NB-4 cells to ellipticine need to be answered. Therefore, this feature was studied.

\section{Materials and methods}

Cell lines and cell culture. UKF-NB-4 neuroblastoma cell line, established from recurrent bone marrow metastases of high risk neuroblastoma, was a gift of Professor J. Cinatl (J.W. Goethe University, Frankfurt, Germany). The ellipticine-resistant cell line, designated UKF-NB-4 ${ }^{\mathrm{ELL}}$, was established by exposing
UKF-NB-4 cells to increasing concentrations from 0.2 to $2.5 \mu \mathrm{M}$ ellipticine over 36 months. The drug resistance of UKF-NB-4 ${ }^{\mathrm{ELLI}}$ cells to ellipticine was verified using the MTT test (17). Each cell line was cultivated in Iscove's modified Dulbecco's medium (IMDM) supplemented with $10 \%(\mathrm{v} / \mathrm{v})$ fetal bovine serum (both from Life Technologies, Carlsbad, CA, USA), maintained at $37^{\circ} \mathrm{C}$ and $5 \% \mathrm{CO}_{2}$. The medium for UKF-NB- $4^{\mathrm{ELLI}}$ cells was the same, but contained $2.5 \mu \mathrm{M}$ ellipticine (8). Resistance of UKF-NB-4 ${ }^{\text {ELLI }}$ cells to ellipticine caused by changes in expression of several genes and chromosome modifications (detailed in ref. 17) is maintained during more than four passages of these cells without ellipticine (17). Before experiments, UKF-NB-4 $4^{\mathrm{ELLI}}$ cells were cultivated for at least one passage without ellipticine, in order to remove ellipticine from these cells. Ellipticine, chloroquine, wortmannin and bafilomycin A were obtained from Sigma-Aldrich (St. Louis, MO, USA).

Electron microscopy. UKF-NB-4 and UKF-NB-4 $4^{\mathrm{ELLI}}$ cells $\left(5 \times 10^{5}\right)$ were grown on glass $60 \mathrm{~mm}$ dishes either untreated or treated with $5 \mu \mathrm{M}$ ellipticine and $100 \mathrm{nM}$ bafilomycin A as well as combination of $5 \mu \mathrm{M}$ ellipticine and $100 \mathrm{nM}$ bafilomycin A for $1 \mathrm{~h}$ at $37^{\circ} \mathrm{C}$. In the case of a combined treatment, bafilomycin A was added to the incubations 20 min before adding ellipticine. Cells were mechanically re-suspended, washed, centrifuged and fixed with $2.5 \%$ glutaraldehyde in $0.1 \mathrm{M}$ sodium cacodylate buffer pH 7.4 for $90 \mathrm{~min}$. Samples were centrifuged $(16,000 \mathrm{x}$ g for $5 \mathrm{~min})$ and pellets were postfixed for $60 \mathrm{~min}$ with $2 \% \mathrm{OsO}_{4}$ in $0.1 \mathrm{M}$ sodium cacodylate buffer $\mathrm{pH}$ 7.4, dehydrated in graded series of alcohol and embedded in a Durcupan-Epon mixture. Ultrathin sections were prepared on Leica EM UC6 ultramicrotome (Leica Microsystems, Vienna, Austria) contrasted with uranyl acetate and lead citrate and examined by a JEM 1011 transmission electron microscope (Jeol, Tokyo, Japan).

Fluorescence microscopy. Acidic vesicular organelle stained, UKF-NB-4 cells $\left(5 \times 10^{5}\right)$ were grown on $35 \mathrm{~mm}$ glass bottom culture dishes (In Vitro Scientific, Sunnyvale, CA, USA) for $24 \mathrm{~h}$ before adding the compounds. Cells were treated either with $5 \mu \mathrm{M}$ ellipticine alone or in combination with either $100 \mathrm{nM}$ bafilomycin A or $25 \mu \mathrm{M}$ chloroquine for $1 \mathrm{~h}$ at $37^{\circ} \mathrm{C}$, then incubated with $75 \mathrm{nM}$ LysoTracker ${ }^{\circledR}$ Red (Life Technologies) for $30 \mathrm{~min}$. After washing with Hanks' balanced salt solution (Sigma-Aldrich), cells were observed with a laserscanning confocal microscope, Olympus FV1000 (Olympus, Tokyo, Japan). For excitation of the LysoTracker ${ }^{\circledR}$ Red, laser with an excitation wavelength of $559 \mathrm{nM}$ was used; emitted light was collected in the range of 570-670 nM. For excitation of green-ellipticine fluorescence, solid-state laser with an excitation wavelength of $473 \mathrm{nM}$ was used and emitted light was collected in the range of 485-545 $\mathrm{nM}$. All images were recorded with a $x 40$ objective using a zoom factor of $x 2$ and the Olympus FluoView FV1000 system. Each fluorescence channel was scanned individually (sequential scanning). Fluorescent channels were pseudocolored with RGB values corresponding to each of the fluorophore emission spectral profiles.

Western blot analysis of V-ATPase (ATP6VOD1 membrane domain) protein expression. In order to analyze V-ATPase 
(ATP6V0D1 membrane domain) protein expression, western blotting was used. UKF-NB-4 and UKF-NB-4 ${ }^{\text {ELLI }}$ cell $\left(1.5 \times 10^{6}\right)$ pellets were re-suspended in $25 \mathrm{mM}$ Tris- $\mathrm{HCl}$ buffer $\mathrm{pH} 7.6$ containing $150 \mathrm{mM} \mathrm{NaCl}, 1 \%$ detergent Igepal ${ }^{\circledR} \mathrm{CA}-630$ (Sigma Chemical Co., St. Louis, MO, USA), 1\% sodium deoxycholate and $0.1 \%$ sodium dodecyl sulfate (SDS) and with solution of Complete ${ }^{\mathrm{TM}}$ (Roche, Basel, Switzerland) at concentrations described by the provider. The samples were incubated for $30 \mathrm{~min}$ on ice and thereafter centrifuged for $20 \mathrm{~min}$ at $20,000 \mathrm{x} \mathrm{g}$ and $4^{\circ} \mathrm{C}$. Supernatants were used for additional analysis. Protein concentrations were assessed using the DC protein assay (Bio-Rad, Hercules, CA, USA) according to Lowry method. Proteins $(15 \mu \mathrm{g})$ were electrophoretically separated using 4-20\% TGX precast gel (100 mA). After migration, proteins were transferred to a nitrocellulose membrane and incubated with $5 \%$ non-fat milk to block non-specific binding. The membranes were then exposed to specific anti-ATP6V0D1 mouse monoclonal antibody (1:500; Abcam, Cambridge, UK). Membranes were washed and exposed to peroxidase-conjugated anti-IgG secondary antibodies (1:2,000; Bio-Rad) and the antigen-antibody complex was visualized by enhanced chemiluminescence detection system according to the manufacturer's instructions (ImmunStar HRP Substrate; Bio-Rad), using X-ray film (MEDIX XBU; Foma, Hradec Kralove, Czech Republic). Antibody against actin (1:1,000; Sigma-Aldrich) was used as loading control.

Determination of apoptosis by Annexin V/DAPI labeling. UKF-NB-4 and UKF-NB-4 ${ }^{\text {ELLI }}$ cells $\left(5 \times 10^{5}\right)$ were seeded in 35-mm culture dishes overnight. Bafilomycin A, chloroquine and/or ellipticine in the above-mentioned concentrations were added to dishes and the cells were incubated for $24 \mathrm{~h}$. The cells were collected by trypsinization and washed with phosphatebuffered saline (PBS). Annexin V staining was accomplished by following producer's instructions (Exbio, Vestec, Czech Republic). The cells were re-suspended in Annexin $\mathrm{V}$ binding buffer (Exbio), then Annexin V-Dy647 was added and samples were incubated for $15 \mathrm{~min}$ in the dark at ambient temperature. DAPI $(2.5 \mu \mathrm{g} / \mathrm{ml})$ was added just before analysis. Cells were analyzed using LSR II Flow Cytometer (BD Bioscience, San Jose, CA, USA).

3-(4,5-Dimethylthiazol-2-yl)-5-(3-carboxymethoxyphenyl)-2(4-sulfophenyl)-2H-tetrazolium (MTS) assay. The $\mathrm{IC}_{50}$ values of ellipticine were determined by CellTiter $96^{\circledR}$ AQueous One Solution Cell Proliferation Assay (Promega, Fitchburg, WI, USA) in a 96-well plate. For a dose-response curve, cells were seeded in $100 \mu \mathrm{l}$ of medium with $5 \times 10^{3}$ cells/well with $100 \mathrm{nM}$ bafilomycin A, $25 \mu \mathrm{M}$ chloroquine or $100 \mathrm{nM}$ wortmanin, and 20 min later ellipticine, in serial dilutions, was added. After three days of incubation at $37^{\circ} \mathrm{C}$ in $5 \% \mathrm{CO}_{2}, 7 \mu \mathrm{l}$ of MTS solution per well was added and the plates were incubated for $2 \mathrm{~h}$. The absorbance at $490 \mathrm{nM}$ was measured for each well by multiwell ELISA reader VersaMax (Molecular Devices, Sunnyvale, CA, USA). Each value is the mean of 8 wells. The mean absorbance of medium controls was the background and was subtracted. The $\mathrm{IC}_{50}$ values were calculated from three independent experiments using the linear regression of the dose-log response curves by SoftMaxPro software.
Western blot analysis of autophagosomal marker proteins LC3-I and LC3-II. To induce autophagy, UKF-NB-4 and UKF-NB-4 ${ }^{\text {ELLI }}$ cells were starved in Hanks' balanced salt solution (Sigma-Aldrich) for $4 \mathrm{~h}$ at $37^{\circ} \mathrm{C}$ with or without the inhibitors of autophagy, wortmannin $(0.1 \mu \mathrm{M})$, chloroquine $(25 \mu \mathrm{M})$ or bafilomycin A (100 nM). Subsequently cells were collected and lysed in a Laemmli sample buffer (Sigma-Aldrich) and were subjected to immunoanalysis. Protein concentrations were assessed using a DC protein assay kit (Bio-Rad) according to manufacturer's instructions. Sample protein $(50 \mu \mathrm{g})$ was subjected to SDS-polyacrylamide gel electrophoresis. After migration, proteins were transferred to nitrocellulose membranes and incubated with 5\% non-fat milk (Bio-Rad). The membranes were exposed to anti-LC3 (microtubule-associated protein 1A/1B-light chain 3) antibody diluted 1:400 (Novus Biologicals, Littleton, CO, USA) overnight at $4^{\circ} \mathrm{C}$. Membranes were then washed three times with PBS/Tween-20 and exposed to horseradish peroxidase-conjugated goat anti-rabbit anti-IgG $(\mathrm{H}+\mathrm{L})$ secondary antibodies (Bio-Rad). The antigen-antibody complex was visualized using chemiluminescence by Immun-Star HRP Substrate kit (Bio-Rad). Antibodies against actin (1:1,000; Sigma-Aldrich) were used as loading control.

DNA isolation from neuroblastoma cells and ${ }^{32} P$-postlabeling of ellipticine-DNA adducts. Neuroblastoma cell lines were seeded $24 \mathrm{~h}$ prior to treatment at a density of $5 \times 10^{5}$ cells $/ \mathrm{ml}$ in two $75 \mathrm{~cm}^{2}$ culture flasks in a total volume of $20 \mathrm{ml}$ of IMDM. After $24 \mathrm{~h}$ incubations with $5 \mu \mathrm{M}$ ellipticine in IMDM, the cells were harvested after trypsinizing by centrifugation at $2000 \mathrm{x}$ g for $3 \mathrm{~min}$ and two washing steps with $5 \mathrm{ml}$ of PBS yielded a cell pellet, which was stored at $-80^{\circ} \mathrm{C}$ until DNA isolation. An analogous procedure was used to evaluate the effect of treatment of neuroblastoma cells with bafilomycin A or chloroquine before adding ellipticine. Cells were treated with $100 \mathrm{nM}$ bafilomycin A or $25 \mu \mathrm{M}$ chloroquine for $20 \mathrm{~min}$ before adding ellipticine. DNA from neuroblastoma cells treated with $5 \mu \mathrm{M}$ ellipticine in the presence or absence of $100 \mathrm{nM}$ bafilomycin $\mathrm{A}$ and/or $25 \mu \mathrm{M}$ chloroquine for $24 \mathrm{~h}$ was isolated by the phenol-chloroform extraction as described $(8,9,13,27,28)$. The ${ }^{32} \mathrm{P}$-postlabeling of nucleotides using nuclease P1 enrichment, found previously to be appropriate to detect and quantify ellipticine-derived DNA adducts formed in vitro $(12,13,27-30)$ and in vivo $(6,7,31-33)$ was used.

Statistical analysis. Data are expressed as mean \pm standard deviations (SD). Student's t-test (two-tailed) was used for statistical analysis. P-values $<0.05$ were considered statistically significant, and are indicated in the figures as ${ }^{*} \mathrm{P}<0.05$, ${ }^{* *} \mathrm{P}<0.01$ and ${ }^{* * *} \mathrm{P}<0.001$.

\section{Results}

Ellipticine induces cytoplasmic vacuolization in neuroblastoma cells and accumulates in these vacuoles. Treatment of neuroblastoma UKF-NB-4 cells, both sensitive and resistant (UKF-NB-4 ${ }^{\mathrm{ELLI}}$ ) to ellipticine, with ellipticine at concentrations that are toxic to these cells $(5 \mu \mathrm{M})$ induced extensive cytoplasmic vacuolization in these cells (vacuoles are indicated by arrows in Fig. 1B and E). The higher number of 

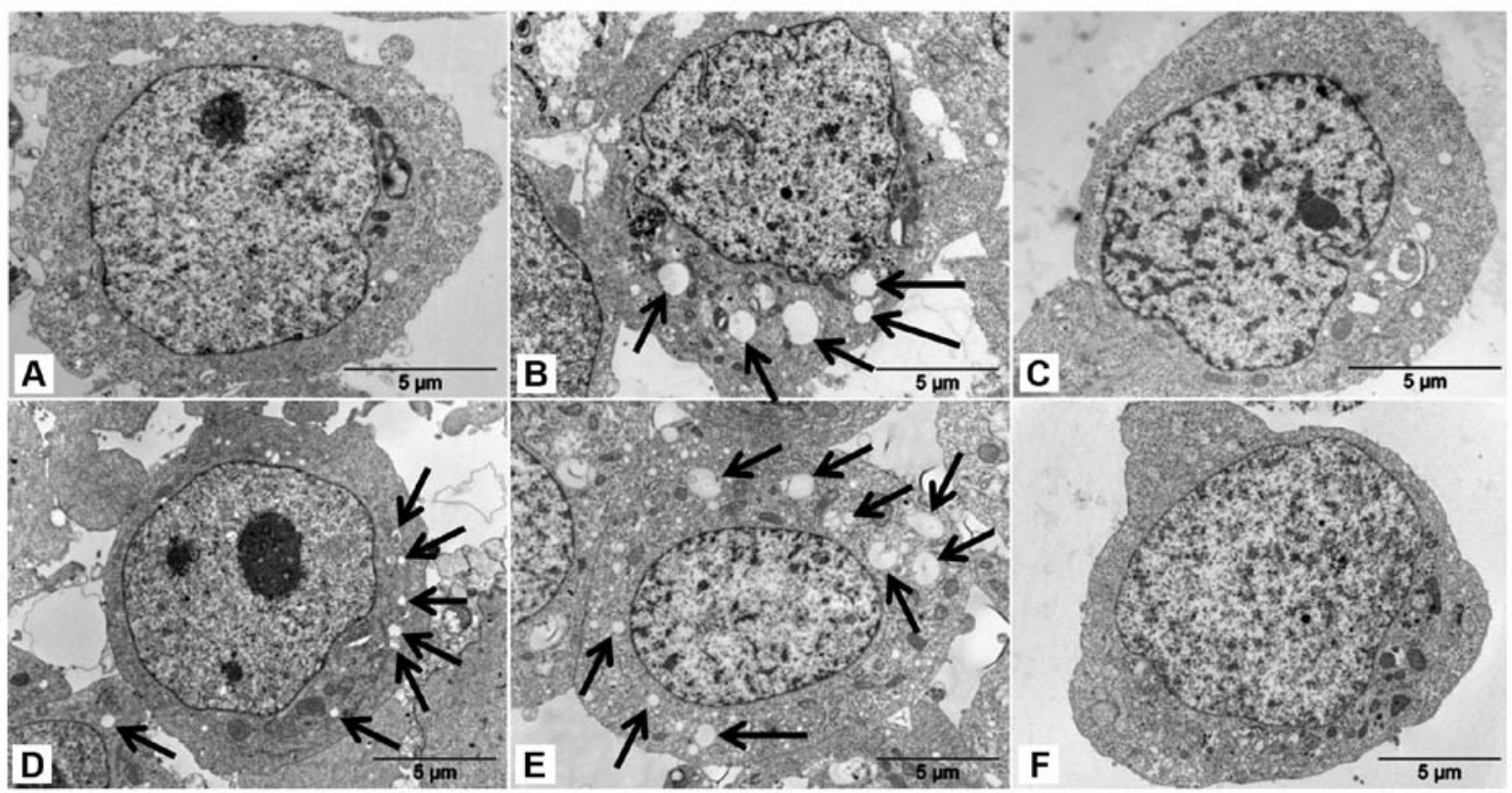

Figure 1. Transmission electron microscope images show a significant vacuolization of cytoplasm in (A-C) UKF-NB-4 ellipticine-sensitive and (D-F) UKF-NB-4 ${ }^{\text {ELLI }}$ ellipticine resistant cell lines after exposure to ellipticine. UKF-NB-4 cell line (A) control; (B) $1 \mathrm{~h}$ incubation with $5 \mu \mathrm{M}$ ellipticine; (C) $1 \mathrm{~h}$ incubation with $100 \mathrm{nM}$ bafilomycin A and $5 \mu \mathrm{M}$ ellipticine; UKF-NB-4 ${ }^{\mathrm{ELLI}}$ cell line (D) control; (E) $1 \mathrm{~h}$ incubation with $5 \mu \mathrm{M}$ ellipticine; (F) $1 \mathrm{~h}$ incubation with $100 \mathrm{nM}$ bafilomycin A and $5 \mu \mathrm{M}$ ellipticine. (C and F) Demonstrate disappearance of cytoplasmic vacuolization after co-incubation with vacuolar (V)-ATPase inhibitor bafilomycin A and ellipticine in both cell lines. Locations of vacuoles are indicated by arrows. Representative data from one of three independent experiments are shown.

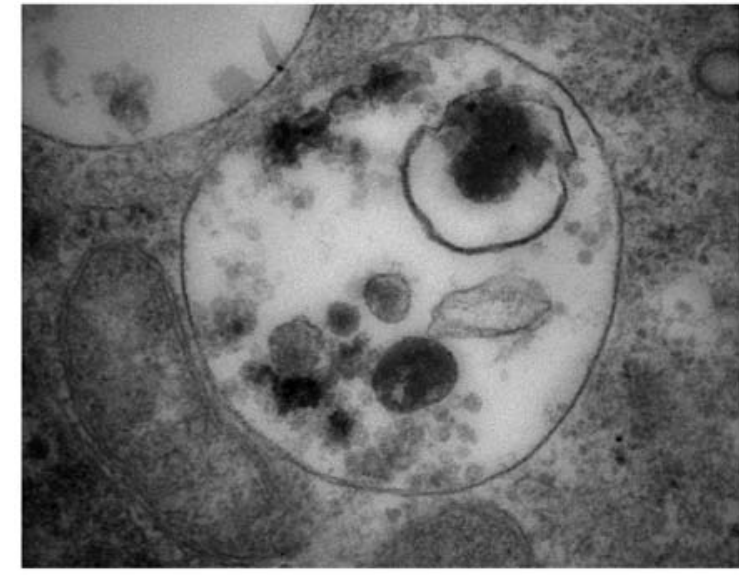

Figure 2. Transmission electron microscope image shows a detail of one vacuole (a white vacuole formed in a UKF-NB-4 cell line by treating with $5 \mu \mathrm{M}$ ellipticine) located close to mitochondria. The vacuole is lined by a single membrane that ruled out autophagy. It contains some heterogeneous material (darker structures in this vacuole). Representative data from one of three independent experiments are shown.

these vacuoles was generated in UKF-NB-4 ${ }^{\mathrm{ELLI}}$ cells resistant to ellipticine than in the parent UKF-NB-4 cell line. The vacuolar vesicles of a small size were also present in the UKF-NB-4 ${ }^{\text {ELLI }}$ cell line prepared by cultivation of UKF-NB-4 cells with increasing concentrations of ellipticine (from 0.2 to $2.5 \mu \mathrm{M}$ ) over 36 months (17) (vesicles are indicated by arrows in Fig. 1D). The vacuoles were already detectable $30 \mathrm{~min}$ after adding the ellipticine (data not shown). This ellipticinemediated cytoplasmic vacuolization seems to be a general phenomenon, because it appears also in the neuroblastoma cell lines SK-N-AS and UKF-NB-3 (data not shown). Under the electron microscope, ellipticine-induced vacuoles were found to be electron-lucent and to contain some heterogeneous material (the darker structures in a vacuole shown in Fig. 2). They, however, lacked any detectable content of cytoplasmic material (organelles) and were lined by a single membrane (Fig. 2), ruling out autophagy. Nevertheless, in order to characterize the vacuoles further, we used confocal microscopy of cells stained with two specific lysosomal markers, lysosomal-associated membrane protein 1 (LAMP1) (34) and a lysosomal marker selective for acidic compartments, LysoTracker ${ }^{\circledR}$ Red (35). Unfortunately, the use of LAMP1 as a marker failed in our experiments, because LAMP1 could not be applied simultaneously with ellipticine. The anti-LAMP1 is namely used on fixed cells and fixation interferes with ellipticine detection (data not shown). The results found using confocal microscopy of cells stained with LysoTracker ${ }^{\circledR}$ Red (Fig. 3) and the finding that the ellipticine-induced vacuoles are single membrane vesicles (Figs. 1 and 2) suggested that these vacuoles are lysosomes.

The green fluorescence of ellipticine (excitation, $440 \mathrm{nM}$; emission, $520 \mathrm{~nm}$ ) (10) allowed the detection of its intracellular localization. At physiological $\mathrm{pH}$, ellipticine exists in both protonated (charged) and unprotonated (uncharged) forms (7). As shown in Fig. 3, the UKF-NB-4 cells exposed to ellipticine contained ellipticine-specific green fluorescent vesicles where ellipticine is accumulated. Some of the vesicles where ellipticine was present colocalized with a lysosomal marker LysoTracker ${ }^{\circledR}$ Red (Fig. 3). Hence, ellipticine as a protonated chemical is trapped in these vesicles formed in the cells. This may be caused by the pKa value of this compound and the $\mathrm{pH}$ gradient between cytoplasm and acidic vacuoles developed by ellipticine. Namely, ellipticine has a pKa of $\sim 6$, and can be protonated in a weakly acidic environment $(7,36,37)$. The 


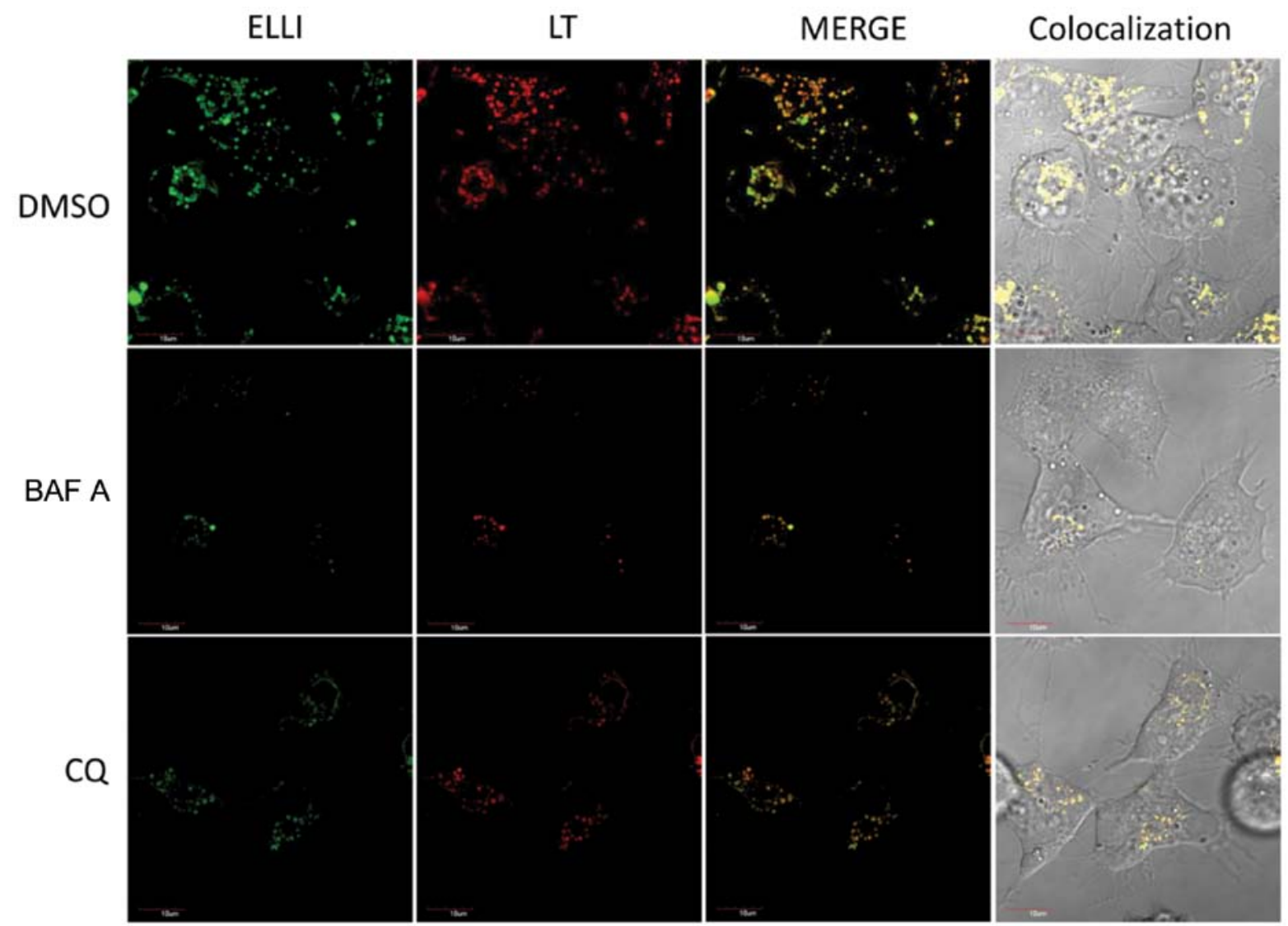

Figure 3. Confocal microscope images demonstrate colocalization (yellow/orange color in MERGE or yellow in colocalization) of ellipticine (green ELLI, $5 \mu \mathrm{M}$ ) and LysoTracker (red LT, $75 \mathrm{nM}$ ), a marker of the acidic lysosomal compartment, in UKF-NB-4 cells. Cells were incubated with $5 \mu \mathrm{M}$ ellipticine (dissolved in DMSO) without or with $100 \mathrm{nM}$ bafilomycin A (Baf A) or $25 \mu \mathrm{M}$ chloroquine (CQ) as described in the Materials and methods, and examined by confocal microscopy. Representative data from one of three independent experiments are shown.

A
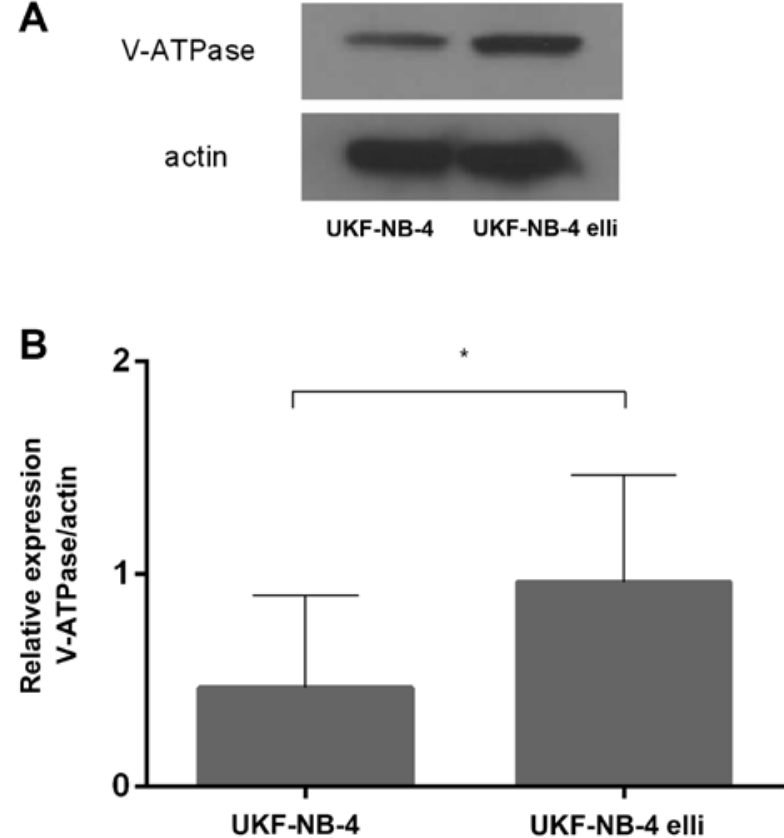

Figure 4. Expression of vacuolar (V)-ATPase (ATP6V0D1) protein detected by western blotting in UKF-NB-4 ellipticine-sensitive and UKF-NB-4 ellipticine-resistant cell lines. Actin was used as loading control. (A) Representative western blotting. (B) V-ATPase expressed relative to levels of actin. (B) Average and standard deviations (SD) from three independent experiments are shown. Values significantly different from individual cell lines (UKF-NB-4 or UKF-NB-4 ${ }^{\mathrm{ELLI}}$ ), ${ }^{*} \mathrm{P}<0.05$ (Student's t-test). trapping of ellipticine in these acidic vesicles is followed by osmotic swelling and dilatation (Fig. 1).

A contribution of V-ATPase to ellipticine-induced vacuolation and ellipticine sequestration into these vacuoles was investigated with its specific inhibitor, bafilomycin A $(38,39)$ and the lysosomotropic drug chloroquine, the agent that enters selectively the lysosomes and inhibits enzymes for which the acidic $\mathrm{pH}$ is crucial (40).

Ellipticine-induced vacuolation and intravesicular ellipticine-associated fluorescence were abolished by co-treatment of tested neuroblastoma cells with bafilomycin A and chloroquine (Figs. 1 and 3 ). These results suggest that ellipticine is responsible for the V-ATPase-mediated formation of cytoplasmic vacuoles (i.e. lysosomes) in these neuroblastoma cells, and that is able to be sequestrated into these acidic compartments.

Expression of V-ATPase in the ellipticine sensitive and resistant $U K F-N B-4$ cells. Because of the suspected role of upregulation of the $V$-ATPase gene in induction of resistance of UKF-NB-4 cells to ellipticine (17), we further investigated expression of this enzyme both in the ellipticine sensitive and resistant UKF-NB-4 cells. Using western blot analyses, expression of a protein product of ATP6VOD1, the gene of the $\mathrm{V}$-ATPase membrane domain, which is upregulated in several drug-resistant cell lines including UKF-NB-4 ${ }^{\text {ELLI }}(17,38-43)$, was measured in the tested cells. As shown in Fig. 4, the 
Table I. The effect of bafilomycin A, chloroquine and wortmannin on the $\mathrm{IC}_{50}$ values for ellipticine in ellipticine-sensitive UKF-NB-4 and ellipticine-resistant UKF-NB-4 ${ }^{\mathrm{ELLI}}$ neuroblastoma cell lines.

$\mathrm{IC}_{50}$ for ellipticine $(\mu \mathrm{M})$

\begin{tabular}{lcc}
\cline { 2 - 3 } Compound & UKF-NB-4 cells & UKF-NB-4 \\
\hline ELLI cells \\
Ellipticine & $0.86 \pm 0.007$ & $1.42 \pm 0.004^{\mathrm{c}}$ \\
Ellipticine $+100 \mathrm{nM}$ bafilomycin A $+25 \mu \mathrm{M}$ chloroquine & $0.21 \pm 0.006^{\mathrm{a}}$ & $0.69 \pm 0.014^{\mathrm{a}, \mathrm{c}}$ \\
Ellipticine $+100 \mathrm{nM}$ wortmannin & $0.19 \pm 0.010^{\mathrm{a}}$ & $0.35 \pm 0.012^{\mathrm{a}, \mathrm{c}}$ \\
& $1.02 \pm 0.005^{\mathrm{b}}$ & $1.39 \pm 0.014^{\mathrm{c}}$
\end{tabular}

$\mathrm{IC}_{50}$ values determined by the MTS test (Materials and methods) were calculated from the linear regression of the dose-log response curves. Values are mean \pm SD of three experiments. The data were analyzed statistically by Student's t-test. Values significantly different from individual cell lines (UKF-NB-4 or UKF-NB-4 ${ }^{\mathrm{ELLI}}$ ) cultivated with ellipticine alone, ${ }^{\mathrm{a}} \mathrm{P}<0.001$ and ${ }^{\mathrm{b}} \mathrm{P}<0.01$. Values significantly different from UKF-NB-4 cells, ${ }^{\mathrm{C}} \mathrm{P}<0.001$.

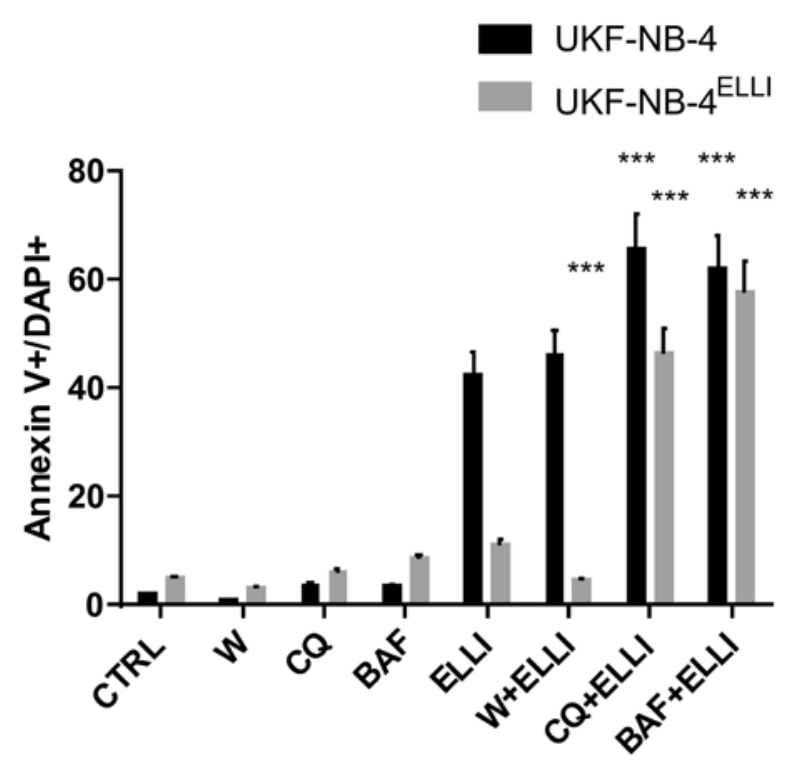

Figure 5. Detection of apoptosis induced in UKF-NB-4 and UKF-NB$4^{\mathrm{ELLI}}$ neuroblastoma cells using the Annexin V/DAPI labeling after $24 \mathrm{~h}$ incubation with $5 \mu \mathrm{M}$ ellipticine (ELLI) and the inhibitors bafilomycin A (BAF, $100 \mathrm{nM}$ ), chloroquine (CQ, $25 \mu \mathrm{M})$, or wortmannin (W, $100 \mathrm{nM}$ ) Bafilomycin A and chloroquine, but not wortmannin, potentiate the anticancer effect of ellipticine. Average and standard deviations (SD) from three independent experiments are shown. Values significantly different from individual cell lines (UKF-NB-4 or UKF-NB-4 ${ }^{\mathrm{ELLI}}$ ) cultivated with ellipticine alone, ${ }^{* * * *} \mathrm{P}<0.001$ (Student's t-test).

V-ATPase (ATP6V0D) protein levels were 2.3-times higher in the resistant UKF-NB- $4^{\mathrm{ELLI}}$ cell line than in its parental sensitive line. These results are in agreement with previous finding which demonstrated upregulation of the ATP6VODI gene in ellipticine-resistant neuroblastoma cells (17), and point out its importance for acquiring resistance to ellipticine.

Treatment of neuroblastoma cells with bafilomycin A or chloroquine increases the cytotoxic effects of ellipticine and decreases their resistance to ellipticine. The UKF-NB-4 and UKF-NB- $4^{\mathrm{ELLI}}$ cell lines were treated with either ellipticine alone or after pretreatment with bafilomycin A or chloroquine. The cytotoxic effects of ellipticine to neuroblastoma cells in the presence or absence of these inhibitors were analyzed by two methods: i) by detection of apoptosis in the cells using Annexin V/DAPI labeling (Fig. 5) and ii) by MTS assay (Table I). Treatment of neuroblastoma cells with bafilomycin A or chloroquine did not induce apoptosis in these cells (Fig. 5). However, pretreatment of the cells with these compounds enhanced markedly the ellipticine-mediated apoptosis induction in both the sensitive and ellipticineresistant neuroblastoma cells and decreased the resistance of UKF-NB-4 ${ }^{\mathrm{ELLI}}$ cells to ellipticine (Fig. 5). In addition, pretreatment of cells with bafilomycin A and/or chloroquine was able to reduce the values of $\mathrm{IC}_{50}$ both in the ellipticinesensitive and ellipticine-resistant cell lines to the lower $\mathrm{IC}_{50}$ values (Table I). These results demonstrate that a decrease in sensitivity of neuroblastoma cells to ellipticine is indeed caused by the potency of this drug to induce the formation of acidified vesicles having the lysosomal character in these cells, which additionally trapped the protonated ellipticine, thereby decreasing its cytotoxic effects. They also strongly support the suggestion that these processes participated in ellipticine-induced resistance of UKF-NB-4 cells.

Nevertheless, it should be noted that bafilomycin A and chloroquine act not only as the inhibitors of lysosomal proteases, but that they can also partially prevent maturation of autophagic vacuoles. They, namely, also inhibit fusion between autophagosomes and lysosomes, because they are inhibitors of the late phase of autophagy (40). Hence, their augmented effects may be caused also by authophagy inhibition. Here, we examined this possibility, namely, whether their potentiating effect on ellipticine-mediated cytotoxicity to neuroblastoma cells is related to autophagy inhibition. For such a study, we used the inhibitor of phosphatidylinositol 3-kinase (PI3K) wortmannin $(44,45)$, since, as an inhibitor of this enzyme $(44,45)$, it dictates the autophagy development in cells (46). In contrast to bafilomycin A and chloroquine, wortmannin had no effect on induction of apoptosis in neuroblastoma cells exposed to ellipticine (Fig. 5). It did not reduce the value of $\mathrm{IC}_{50}$ for ellipticine in these cells (Table I). These findings demonstrate that the bafilomycin A- and chloroquinemediated increase in cytotoxicity and induction of apoptosis caused by ellipticine determined in this study are not related to autophagy. 
Table II. DNA adduct formation by ellipticine in UKF-NB-4 and UKF-NB-4 ${ }^{\text {ELLI }}$ cell lines.

$\mathrm{RAL}\left(\text { mean } \pm \mathrm{SD} / 10^{7} \text { nucleotides }\right)^{\mathrm{a}}$

\begin{tabular}{|c|c|c|c|c|c|}
\hline Cells & Adduct $1^{\mathrm{b}}$ & Adduct $2^{\mathrm{b}}$ & Adduct $6^{\mathrm{b}}$ & Adduct $7^{\mathrm{b}}$ & Total \\
\hline \multicolumn{6}{|l|}{ UKF-NB-4 } \\
\hline ELLI & $2.92 \pm 0.85$ & $1.75 \pm 0.78$ & $0.55 \pm 0.03$ & $0.51 \pm 0.005$ & $5.73 \pm 1.51$ \\
\hline $\mathrm{BAF}+\mathrm{ELLI}$ & $4.3 \pm 0.67^{\mathrm{c}}$ & $2.03 \pm 0.12^{\mathrm{d}}$ & $0.69 \pm 0.03^{\mathrm{c}}$ & $0.60 \pm 0.03^{c}$ & $7.62 \pm 0.41^{\mathrm{c}}$ \\
\hline CQ + ELLI & $4.08 \pm 0.72^{c}$ & $2.64 \pm 0.14^{\mathrm{e}}$ & $0.91 \pm 0.04^{\mathrm{e}}$ & $0.77 \pm 0.4^{\mathrm{e}}$ & $8.4 \pm 0.53^{c}$ \\
\hline \multicolumn{6}{|l|}{ UKF-NB-4 ${ }^{\text {ELLI }}$} \\
\hline ELLI & $1.02 \pm 0.01^{\mathrm{g}}$ & $0.89 \pm 0.01^{\mathrm{g}}$ & $0.5 \pm 0.01$ & $0.03 \pm 0.01^{\mathrm{g}}$ & $1.99 \pm 0.06^{\mathrm{g}}$ \\
\hline $\mathrm{BAF}+\mathrm{ELLI}$ & $1.69 \pm 0.21^{\mathrm{c}, \mathrm{g}}$ & $1.65 \pm 0.07^{e, f}$ & $0.6 \pm 0.03^{c}$ & $0.22 \pm 0.01^{\mathrm{e}, \mathrm{g}}$ & $4.16 \pm 0.36^{e, f}$ \\
\hline CQ + ELLI & $1.78 \pm 0.1^{\mathrm{e}, \mathrm{g}}$ & $1.82 \pm 0.11^{\mathrm{e}, \mathrm{f}}$ & $0.51 \pm 0.03^{f}$ & $0.41 \pm 0.02^{\mathrm{e}, \mathrm{g}}$ & $4.52 \pm 0.33^{\mathrm{e}, \mathrm{g}}$ \\
\hline
\end{tabular}

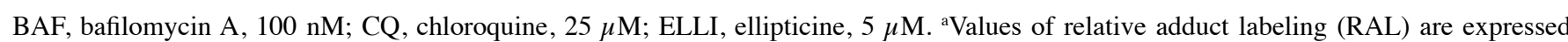
as adducts $/ 10^{7}$ normal nucleotides. Values are mean $\pm \mathrm{SD}$ of three experiments. ${ }^{\mathrm{b}}$ See Fig. 7 insert. ${ }^{\mathrm{c} \text { e }}$ Statistical significance of differences between the levels of RALs determined in DNA of the cells cultivated with ellipticine and those with ellipticine and bafilomycin A or chloroquine $\left({ }^{\mathrm{C}} \mathrm{P}<0.01,{ }^{\mathrm{d}} \mathrm{P}<0.05\right.$ and $\left.{ }^{\mathrm{e}} \mathrm{P}<0.001\right)$. ${ }^{\mathrm{f} \text { and } \mathrm{g}}$ Statistical differences between the levels of RALs determined in DNA of the UKF-NB-4 and UKF-NB- $4{ }^{\text {ELLI }}$ cell lines ( ${ }^{\mathrm{P}} \mathrm{P}<0.01$ and $\left.{ }^{\mathrm{g}} \mathrm{P}<0.001\right)$ as calculated by Student's t-test.

A

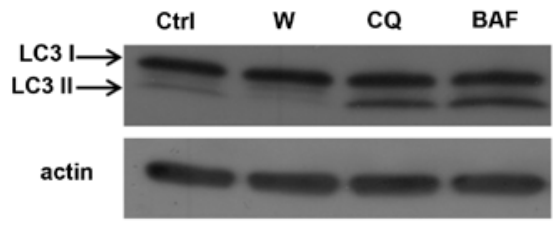

B

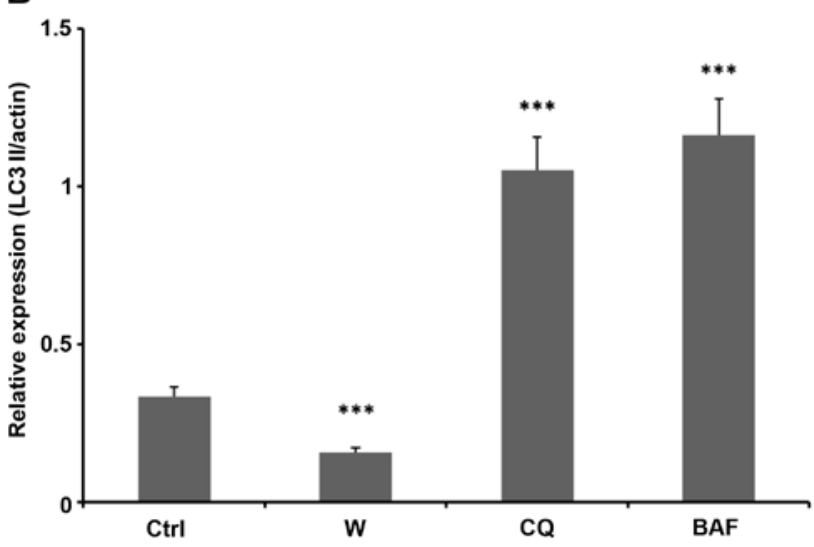

Figure 6. Expression of LC3-I and LC3-II proteins determined by western blotting in UKF-NB-4 cells after treatment with different autophagy inhibitors. Control (Ctrl) cells were cultivated for $4 \mathrm{~h}$ in Hanks' balanced salt solution to induce autophagy. Actin was used as loading control. (A) Representative western blotting. (B) LC3-II expressed relative to levels of actin. Wortmannin (W, $100 \mathrm{nM})$, an inhibitor of autophagosome formation, decreased LC3-II expression (compare lanes Ctrl and W). Chloroquine $(\mathrm{CQ}, 25 \mu \mathrm{M})$ and bafilomycin $\mathrm{A}(\mathrm{BAF}, 100 \mathrm{nM})$ increased lysosomal $\mathrm{pH}$, and consequently decreased activity of lysosomal proteases and degradation of LC3-II (LC3-II expression is increased, lanes CQ and BAF). Experiments verified that the concentrations of inhibitors used are able to inhibit proteolytic processes in the lysosomes (bafilomycin A and chloroquine) or autophagosome formation (wortmannin). (B) Average and standard deviations (SD) from three independent experiments are shown. Values significantly different from control UKF-NB-4 cells, ${ }^{* * *} \mathrm{P}<0.001$ (Student's t-test).

Effectiveness of autophagy inhibitors in tested lines was also investigated by examining the expression of an autophagosomal marker protein LC3-II (Fig. 6), the protein that is highly expressed in both membranes of autophagosomes. Lysosomal turnover of the autophagosomal marker LC3-II namely reflects autophagic activity, and therefore determination of levels of LC3-II is considered as a method suitable to monitor the autophagy process (47). In our experiments, autophagy in neuroblastoma cells was induced by their starvation and proved by expression of LC3-II in these cells (Fig. 6). High expression of LC-II in these cells were also induced by bafilomycin A and chloroquine (Fig. 6) because both these compounds as inhibitors of proteolytic processes in the lysosomes (38-40) increased lysosomal $\mathrm{pH}$ that consequently led to decreased activity of lysosomal proteases. These processes blocked lysosomal degradation and rescued intact LC3-II in neuroblastoma cells (Fig. 6). In contrast, wortmannin as a blocker of autophagosome formation decreased the expression of LC3-II induced by starvation (Fig. 6). This finding again suggests that the increase in ellipticine-mediated cytotoxicity and induction of apoptosis by ellipticine due to bafilomycin A and chloroquine in neuroblastoma cells are not related to autophagy.

Treatment of neuroblastoma cells with bafilomycin A and chloroquine prior to ellipticine increases the formation of covalent ellipticine-derived DNA adducts. Since formation of covalent DNA adducts of ellipticine is one of the major modes of ellipticine action in various cancer cells including neuroblastoma $(6-9,11,12,28,29)$, we investigated whether treatment of UKF-NB-4 and UKF-NB-4 ${ }^{\text {ELLI }}$ cells with bafilomycin A or chloroquine prior to ellipticine changes DNA adduct levels. Two major DNA adducts identical to those formed by the ellipticine metabolites, 13-hydroxy- and 12-hydroxyellipticine, with deoxyguanosine in DNA $(13,15)$, and two minor DNA adducts of unknown structures were detected in neuroblastoma cells treated with ellipticine. The levels of the ellipticine-DNA adducts were lower in a resistant cell line (Fig. 7 and Table II), as it has already been found in our previous study (8). However, 


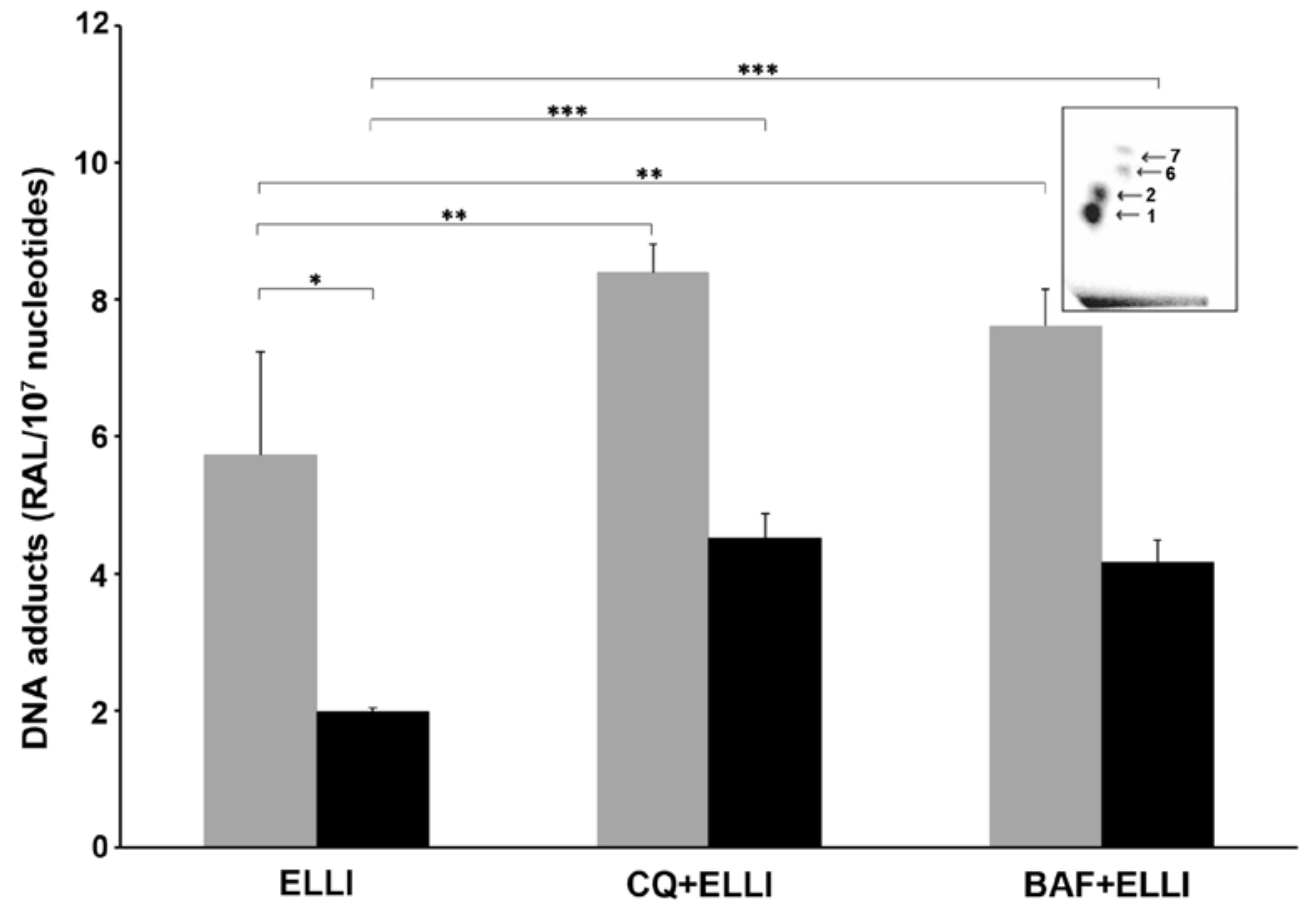

Figure 7. Levels of covalent DNA adducts (sum of adducts 1, 2, 6 and 7 shown in insert) formed in UKF-NB-4 (grey columns) and UKF-NB-4 ${ }^{\text {ELLI }}$ (black columns) neuroblastoma cells after $24 \mathrm{~h}$ treatment with ellipticine (ELLI, $5 \mu \mathrm{M}$ ) either without pretreatment or pretreatment with bafilomycin A (BAF, $100 \mathrm{nM}$ ) or chloroquine $(\mathrm{CQ}, 25 \mu \mathrm{M})$ (the cells were pretreated with bafilomycin A and/or chloroquine for 20 min before adding ellipticine and further incubated $24 \mathrm{~h}$ ). The data represent means of total levels of ellipticine-DNA adducts and standard deviations determined from three independent experiments. Values of relative adduct labeling (RAL) are expressed as adducts $/ 10^{7}$ normal nucleotides. Asterisks represent statistical significance as calculated by Student's t-test $\left({ }^{*} \mathrm{P}<0.05,{ }^{* *} \mathrm{P}<0.01\right.$ and $\left.{ }^{* * * *} \mathrm{P}<0.001\right)$. Insert, an autoradiographic profile of ellipticine-DNA adducts formed in UKF-NB-4 cells determined by ${ }^{32} \mathrm{P}-$ postlabeling. The adduct spots 1 and 2 are formed in deoxyguanosine residues of DNA by the ellipticine metabolites, 13-hydroxy- and 12-hydroxyellipticine (6,7,13,15).

treatment with either bafilomycin A or chloroquine prior to ellipticine significantly increased levels of ellipticine-DNA adducts in both cell lines (Fig. 7 and Table II). This corresponded to enhanced cytotoxic effects of ellipticine on these cells (Fig. 5). These results indicate that bafilomycin A- and chloroquine-mediated inhibition of ellipticine sequestration into vacuoles led to higher concentrations of ellipticine in cytoplasm and nuclei to be activated to species forming covalent DNA adducts.

\section{Discussion}

The results found in this study demonstrate for the first time that sequestration of anticancer drug ellipticine into the subcellular compartments (i.e. lysosomes) of UKF-NB-4 neuroblastoma cells is one of the mechanisms contributing to the development of ellipticine-resistance in these cells. Such processes finally result in a decrease in ellipticine cytotoxic effects $(8,17)$. We demonstrated that this resistance is, among other mechanisms, dependent on upregulation of the $V$-ATPase gene (17). Indeed, here we found that the V-ATPase protein expression is enhanced in the ellipticine-resistant UKF-NB-4 ${ }^{\text {ELLI }}$ cell line.

Since V-ATPase is the major enzyme responsible for the acidification of subcellular compartments, it acidifies newly formed cytoplasmic vacuolar vesicles by pumping protons across the membranes (19-21). This process is a necessary step for additional sequestration of the protonated form of ellipticine within these organelles. Finally, this sequestration results in lower cytoplasmic concentrations of ellipticine, less nuclear accumulation (17) and lower DNA damage by ellipticine (Table II and Fig. 7) and therefore also lower toxic effects to these cells (Table I and Fig. 5) and our previous study (8). The formation of covalent ellipticine-derived DNA adducts, which was found to be lower in ellipticine-resistant UKF-NB$4^{\mathrm{ELLI}}$ cells, was increased by the inhibitor of V-ATPase, bafilomycin $\mathrm{A}$, and/or the lysosomotropic drug chloroquine that blocks formation of lysosomes (48). In concordance to these results, exposure of the tested cells to bafilomycin A and chloroquine enhanced markedly the cytotoxicity of ellipticine on these cells and decreased resistance of UKF-NB-4 ${ }^{\text {ELLI }}$ to ellipticine.

Based on these results, we can conclude that the decrease in ellipticine-mediated cytotoxicity on UKF-NB-4 cells as well as in induction of resistance to ellipticine in the ellipticineresistant UKF-NB-4 ${ }^{\text {ELLI }}$ cell line is associated with vacuolar trapping of this drug, which may be abolished by bafilomycin A or by chloroquine. Therefore, therapeutic implications could be derived from this study. In principle, the components of the endocytic/lysosomal pathway could be molecular targets for a combination therapy of neuroblastoma with chemotherapeutic drugs and probably also for that of other cancers.

\section{Acknowledgements}

This study was supported by GACR (grants P301/10/0356 and 14-8344S), Charles University in Prague (UNCE204025/2012) and by the Ministry of Health of the Czech Republic for conceptual development of research organization 00064203 (University Hospital Motol, Prague, Czech Republic). 


\section{References}

1. Brodeur GM: Neuroblastoma: Biological insights into a clinical enigma. Nat Rev Cancer 3: 203-216, 2003.

2. Schwab M,WestermannF,Hero B and Berthold F: Neuroblastoma: Biology and molecular and chromosomal pathology. Lancet Oncol 4: 472-480, 2003.

3. Morgenstern BZ, Krivoshik AP, Rodriguez V and Anderson PM Wilms' tumor and neuroblastoma. Acta Paediatr (Suppl) 93: $78-85,2004$

4. Kotchetkov R, Driever PH, Cinatl J, Michaelis M, Karaskova J, Blaheta R, Squire JA, Von Deimling A, Moog J and Cinatl J Jr: Increased malignant behavior in neuroblastoma cells with acquired multi-drug resistance does not depend on P-gp expression. Int J Oncol 27: 1029-1037, 2005.

5. Michaelis M, Klassert D, Barth S, Suhan T, Breitling R, Mayer B, Hinsch N, Doerr HW, Cinatl J and Cinatl J Jr: Chemoresistance acquisition induces a global shift of expression of aniogenesisassociated genes and increased pro-angogenic activity in neuroblastoma cells. Mol Cancer 8: 80, 2009.

6. Stiborová M, Rupertová M and Frei E: Cytochrome P450- and peroxidase-mediated oxidation of anticancer alkaloid ellipticine dictates its anti-tumor efficiency. Biochim Biophys Acta 1814: 175-185, 2011.

7. Stiborová M and Frei E: Ellipticines as DNA-targeted chemotherapeutics. Curr Med Chem 21: 575-591, 2014.

8. Poljaková J, Eckschlager T, Hrabeta J, Hrebacková J, Smutný S Frei E, Martínek V, Kizek R and Stiborová M: The mechanism of cytotoxicity and DNA adduct formation by the anticancer drug ellipticine in human neuroblastoma cells. Biochem Pharmacol 77: 1466-1479, 2009.

9. Poljakova J, Hrebackova J, Dvorakova M, Moserova M, Eckschlager T, Hrabeta J, Göttlicherova M, Kopejtkova B, Frei E, Kizek R, et al: Anticancer agent ellipticine combined with histone deacetylase inhibitors, valproic acid and trichostatin A, is an effective DNA damage strategy in human neuroblastoma. Neuro Endocrinol Lett 32 (Suppl 1): 101-116, 2011.

10. Stiborová M, Eckschlager T, Poljaková J, Hraběta J, Adam V, Kizek R and Frei E: The synergistic effects of DNA-targeted chemotherapeutics and histone deacetylase inhibitors as therapeutic strategies for cancer treatment. Curr Med Chem 19: 4218-4238, 2012

11. Stiborova M, Poljakova J, Mrizova I, et al: Expression levels of enzymes metabolizing an anticancer drug ellipticine determined by electromigration assays influence its cytotoxicity to cancer cells - a comparative study. Int J Electrochem Sci 9: 5675-5689, 2014.

12. Stiborová M, Bieler CA, Wiessler M and Frei E: The anticancer agent ellipticine on activation by cytochrome P450 forms covalent DNA adducts. Biochem Pharmacol 62: 1675-1684, 2001.

13. Stiborová M, Sejbal J, Borek-Dohalská L, Aimová D, Poljaková J, Forsterová K, Rupertová M, Wiesner J, Hudecek J, Wiessler M, et al: The anticancer drug ellipticine forms covalent DNA adducts, mediated by human cytochromes P450, through metabolism to 13-hydroxyellipticine and ellipticine N2-oxide. Cancer Res 64 8374-8380, 2004.

14. Stiborova M, Rupertova M, Schmeiser HH and Frei E: Molecular mechanisms of antineoplastic action of an anticancer drug ellipticine. Biomed Pap Med Fac Univ Palacky Olomouc Czech Repub 150: 13-23, 2006.

15. Stiborová M, Poljaková J, Ryslavá H, Dracínský M, Eckschlager T and Frei E: Mammalian peroxidases activate anticancer drug ellipticine to intermediates forming deoxyguanosine adducts in DNA identical to those found in vivo and generated from 12-hydroxyellipticine and 13-hydroxyellipticine. Int J Cancer 120: 243-251, 2007.

16. Kizek R, Adam V, Hrabeta J, Eckschlager T, Smutny S, Burda JV Frei E and Stiborova M: Anthracyclines and ellipticines as DNA-damaging anticancer drugs: Recent advances. Pharmacol Ther 133: 26-39, 2012

17. Procházka P, Libra A, Zemanová Z, Hřebačková J, Poljaková J, Hraběta $J$, Bunček $M$, Stiborová $M$ and Eckschlager $T$ : Mechanisms of ellipticine-mediated resistance in UKF-NB-4 neuroblastoma cells. Cancer Sci 103: 334-341, 2012.

18. Marshansky V, Rubinstein JL and Grüber G: Eukaryotic V-ATPase: Novel structural findings and functional insights Biochim Biophys Acta 1837: 857-879, 2014.

19. Maxfield FR and McGraw TE: Endocytic recycling. Nat Rev Mol Cell Biol 5: 121-132, 2004
20. Goldman SDB, Funk RS, Rajewski RA and Krise JP: Mechanisms of amine accumulation in, and egress from, lysosomes. Bioanalysis 1: 1445-1459, 2009.

21. Coutinho MF, Prata MJ and Alves S: Mannose-6-phosphate pathway: A review on its role in lysosomal function and dysfunction. Mol Genet Metab 105: 542-550, 2012.

22. Simon S, Roy D and Schindler M: Intracellular $\mathrm{pH}$ and the control of multidrug resistance. Proc Natl Acad Sci USA 91: 1128-1132, 1994

23. Mahoney BP, Raghunand N, Baggett B and Gillies RJ: Tumor acidity, ion trapping and chemotherapeutics. I. Acid pH affects the distribution of chemotherapeutic agents in vitro. Biochem Pharmacol 66: 1207-1218, 2003.

24. Chapuy B, Koch R, Radunski U, Corsham S, Cheong N, Inagaki N, Ban N, Wenzel D, Reinhardt D, Zapf A, et al: Intracellular ABC transporter A3 confers multidrug resistance in leukemia cells by lysosomal drug sequestration. Leukemia 22: 1576-1586, 2008.

25. Spugnini EP, Citro G and Fais S: Proton pump inhibitors as anti vacuolar-ATPases drugs: A novel anticancer strategy. J Exp Clin Cancer Res 29: 44, 2010.

26. Yamagishi T, Sahni S, Sharp DM, Arvind A, Jansson PJ and Richardson DR: P-glycoprotein mediates drug resistance via a novel mechanism involving lysosomal sequestration. J Biol Chem 288: 31761-31771, 2013.

27. Frei E, Bieler CA, Arlt VM, Wiessler M and Stiborová M: Covalent binding of the anticancer drug ellipticine to DNA in V79 cells transfected with human cytochrome P450 enzymes. Biochem Pharmacol 64: 289-295, 2002.

28. Poljaková J, Frei E, Gomez JE, Aimová D, Eckschlager T, Hrabeta $\mathbf{J}$ and Stiborová $\mathbf{M}$ : DNA adduct formation by the anticancer drug ellipticine in human leukemia HL-60 and CCRF-CEM cells. Cancer Lett 252: 270-279, 2007.

29. Martinkova E, Dontenwill M, Frei E and Stiborova M: Cytotoxicity of and DNA adduct formation by ellipticine in human U87MG glioblastoma cancer cells. Neuro Endocrinol Lett 30 (Suppl 1): 60-66, 2009.

30. Martinkova E, Maglott A, Leger DY, Bonnet D, Stiborova M, Takeda K, Martin S and Dontenwill M: alpha5beta1 integrin antagonists reduce chemotherapy-induced premature senescence and facilitate apoptosis in human glioblastoma cells. Int $\mathrm{J}$ Cancer 127: 1240-1248, 2010.

31. Stiborová M, Breuer A, Aimová D, Stiborová-Rupertová M, Wiessler $M$ and Frei E: DNA adduct formation by the anticancer drug ellipticine in rats determined by ${ }^{32} \mathrm{P}$ postlabeling. Int $\mathrm{J}$ Cancer 107: 885-890, 2003

32. Stiborová M, Rupertová M, Aimová D, Ryslavá H and Frei E: Formation and persistence of DNA adducts of anticancer drug ellipticine in rats. Toxicology 236: 50-60, 2007.

33. Stiborová M, Arlt VM, Henderson CJ, Wolf CR, Kotrbová V, Moserová M, Hudecek J, Phillips DH and Frei E: Role of hepatic cytochromes $\mathrm{P} 450$ in bioactivation of the anticancer drug ellipticine: studies with the hepatic NADPH:cytochrome P450 reductase null mouse. Toxicol Appl Pharmacol 226: 318-327, 2008.

34. Hunziker W and Geuze HJ: Intracellular trafficking of lysosomal membrane proteins. Bioessays 18: 379-389, 1996

35. Oeste CL, Seco E, Patton WF, Boya P and Pérez-Sala D: Interactions between autophagic and endo-lysosomal markers in endothelial cells. Histochem Cell Biol 139: 659-670, 2013.

36. Garbett NC and Graves DE: Extending nature's leads: The anticancer agent ellipticine. Curr Med Chem Anticancer Agents 4: 149-172, 2004

37. Wu Y, Sadatmousavi P, Wang R, Lu S, Yuan YF and Chen P: Selfassembling peptide-based nanoparticles enhance anticancer effect of ellipticine in vitro and in vivo. Int J Nanomed 7: 3221-3233, 2012.

38. Bowman EJ, Siebers A and Altendorf K: Bafilomycins: A class of inhibitors of membrane ATPases from microorganisms, animal cells, and plant cells. Proc Natl Acad Sci USA 85: 7972-7976, 1988 .

39. Huss M and Wieczorek H: Inhibitors of V-ATPases: Old and new players. J Exp Biol 212: 341-346, 2009.

40. Shacka JJ, Klocke BJ, Shibata M, Uchiyama Y, Datta G, Schmidt RE and Roth KA: Bafilomycin A1 inhibits chloroquineinduced death of cerebellar granule neurons. Mol Pharmacol 69: 1125-1136, 2006

41. Martínez-Zaguilán R, Raghunand N, Lynch RM, Bellamy W, Martinez GM, Rojas B, Smith D, Dalton WS and Gillies RJ: $\mathrm{pH}$ and drug resistance. I. Functional expression of plasmalemmal V-type $\mathrm{H}^{+}$-ATPase in drug-resistant human breast carcinoma cell lines. Biochem Pharmacol 57: 1037-1046, 1999. 
42. Murakami T, Shibuya I, Ise T, Chen ZS, Akiyama S, Nakagawa M, Izumi H, Nakamura T, Matsuo K, Yamada Y, et al: Elevated expression of vacuolar proton pump genes and cellular $\mathrm{PH}$ in cisplatin resistance. Int J Cancer 93: 869-874, 2001.

43. Huang L, Lu Q, Han Y, Li Z, Zhang Z and Li X: ABCG2/ $\mathrm{V}$-ATPase was associated with the drug resistance and tumor metastasis of esophageal squamous cancer cells. Diagn Pathol 7: 180, 2012

44. Wymann MP, Bulgarelli-Leva G, Zvelebil MJ, Pirola L, Vanhaesebroeck B, Waterfield MD and Panayotou G: Wortmannin inactivates phosphoinositide 3-kinase by covalent modification of Lys-802, a residue involved in the phosphate transfer reaction. Mol Cell Biol 16: 1722-1733, 1996.
45. Arcaro A and Wymann MP: Wortmannin is a potent phosphatidylinositol 3-kinase inhibitor: The role of phosphatidylinositol 3,4,5-trisphosphate in neutrophil responses. Biochem J 296: 297-301, 1993

46. Blommaart EF, Krause U, Schellens JP, Vreeling-Sindelárová H and Meijer AJ: The phosphatidylinositol 3-kinase inhibitors wortmannin and LY294002 inhibit autophagy in isolated rat hepatocytes. Eur J Biochem 243: 240-246, 1997.

47. Tanida I, Ueno T and Kominami E: LC3 and sutophagy. Methods Mol Biol 445: 77-88, 2008.

48. Solomon VR and Lee H: Chloroquine and its analogs: A new promise of an old drug for effective and safe cancer therapies. Eur J Pharmacol 625: 220-233, 2009. 